\title{
Methods of Mathematical Modeling of Automated Machine Systems of Multi-Nomenclature Production
}

\author{
Elena Dumler ${ }^{1}$, Roza Vakhitova $^{2}$, Diana Saracheva $^{2}$, Tatyana Makarova ${ }^{2}$ \\ ${ }^{1}$ Ufa State Petroleum Technical University, RU-450064, Ufa, Republic of Bashkortostan, Russia \\ ${ }^{2}$ Almetyevsk State Oil Institute, RU-423450, Tatarstan, Almetyevsk, Russia
}

\begin{abstract}
Automated machine tool systems for multi-product manufacturing were designed for processing parts of a certain nomenclature, which includes separate groups of parts, united by the design, technological, organizational and economic properties. To reduce the number of options in the structure of an automated machine $\mathrm{t}$ ool s ystem, a $\mathrm{t}$ arget nonlinear de sign $\mathrm{f}$ unction $\mathrm{w}$ as applied. $\mathrm{T}$ echnological $\mathrm{c}$ onditions $\mathrm{w}$ ere formulated in such a way as to allow synthesizing alternative structures of the designed automated system. At this stage, a matrix of relations was built and a formalized description of technological conditions was given. Specific and generalized technological conditions, which take into account the graph of relations and compatibility condition formulated for any pa ir of e lements, were c onsidered. The a rticle di scusses the generalized technological conditions obtained on the basis of the synthesis of compatibility and follow-up properties. The existence of generalized technological conditions for the elements of the automated system of the same name was assessed. The interaction of the elements of an automated system during processing, when the condition of the following and compatibility of technological parameters are met, was studied. By analyzing the functional and technological structure of an automated machine tool system for multi-product manufacturing, the k ey r elationships b etween its main el ements were d etermined, an $\mathrm{d}$ the $t$ echnological environment, a key subject of the system research, was identified.
\end{abstract}

\section{Introduction}

The development of integrated c omputer-aided de sign systems $\mathrm{f}$ or a utomated $\mathrm{m}$ achine-tool systems ( CAD ACS) and specialized computer-aided design systems for individual stages of ACC design [1-3] is of great interest for the pr oduction of parts $f$ or multi-product manufacturing system.

In or der $t$ o s olve t he pr oblems of CAD ACC development, designers were first given the task of integrating a utomation $\mathrm{s}$ ystems a nd i nterconnecting systems, s ubsystems, e lements of $t$ hese $s$ ystems a $t$ the stages of $t$ echnological d esign, i ncluding the $\mathrm{c}$ hoice of computer $t$ echnology $[4,5]$. A lthough $t$ he a bovementioned tasks are solved on the basis of system design principles $[6,7]$, th e coordination of $t$ he $r$ eady-to-use solutions a td ifferent ( technological, a lgorithmic, computer, systemic) le vels under the real conditions of ACC design is more difficult [8].

In many ways, production efficiency depends on the rational s election of e quipment. A t $p$ resent, there d oes not exist an no methods for separating huge total sets of equipment and machine tools that are most expedient in terms o ft echnical a nd economic i ndicators for processing parts of a certain nomenclature.

The design of an automated machine tool system is a complex multidimensional task that includes assessment, modeling, synthesis, analysis and optimization of project proposals. $\mathrm{T}$ hese $\mathrm{t}$ asks $\mathrm{c}$ an be $\mathrm{s}$ olved $\mathrm{u}$ sing on ly systematic ap proach, w hich acco unts $f$ or $f$ act t hat the specificity of complex obj ects must i nclude bot $h \mathrm{t}$ he features of their constituent elements and the nature of various relations and connections between them [9].

Typically, a utomated machine to ol s ystems for diversified production are designed for processing parts of a cer tain $\mathrm{n}$ omenclature, which i ncludes s eparate groups of parts, united by design, technological, organizational and economic properties. Therefore, defining a gr oup o $\mathrm{fp}$ arts a nd no menclature is a $\mathrm{n}$ important task [10].Automated machine tool systems for diversified production, as a rule, were designed for processing $\mathrm{p}$ arts o f a cer tain $\mathrm{n}$ omenclature, which included $\mathrm{s}$ eparate $\mathrm{g}$ roups o $\mathrm{f} \mathrm{pa}$ rts, $\mathrm{u}$ nited $\mathrm{b}$ y de sign, technological, o rganizational a nd e conomic characteristics.

\section{Nomenclature and its properties}

Nomenclature is a set of parts that have similar design, functional, te chnological a nd o rganizational characteristics [11].

Formal description of a group of pa rts $D_{2}, 2 \in\{\Gamma\}$, where the nomenclature of parts $\left\{D^{H}\right\}$, processing of which is provided by the synthesized automated system: 


$$
\left\{D_{1}\right\} \cup\left\{D_{2}\right\} \cup \ldots \cup\left\{D_{2}\right\} \cup \ldots \cup\left\{D_{M}\right\}=\left\{D^{H}\right\} .
$$

Let us d efine $\mathrm{t}$ he $\mathrm{p}$ roperties o $\mathrm{ft}$ he $\mathrm{n}$ omenclature, which we select from the subset of elements of the graph $\mathrm{G}=(\mathrm{X}, \mathrm{O}, \mathrm{T}, \mathrm{I}, \mathrm{D})$, which determine the structure of the automated machine to ol s ystem, i. e. Let u s d efine the properties of the nomenclature, which we select from the subset of e lements of the gr aph $\mathrm{G}=(\mathrm{X}, \mathrm{O}, \mathrm{T}, \mathrm{I}, \mathrm{D})$, which determine the structure of the automated machine tool system, i.e.

Nomenclature define properties th at distinguish subsets of e lements of a $\mathrm{g}$ raph $\mathrm{G}=(\mathrm{X}, \mathrm{O}, \mathrm{T}, \mathrm{I}, \mathrm{D})$, determining the structure of the automated machine tool, i.e.

we make the transition from $G=(X, O, T, I)$ to $G *=(X$ ', $\left.O^{\prime}, T^{\prime}, T^{\prime}\right)$, for which the condition:

$$
\left\{X^{\prime}\right\} \subseteq\{X\},\left\{T^{\prime}\right\} \subseteq\{T\},\left\{O^{\prime}\right\} \subseteq\{O\},\left\{I^{\prime}\right\} \subseteq\{I\} .
$$

The s et o $\mathrm{ftr}$ ansitions $\{L\}$ and $\mathrm{t}$ he a ssociated machined surfaces of the set of parts $\{D g\}$ serve as initial parameters $\mathrm{f}$ or $\mathrm{s}$ ynthesizing $\mathrm{t}$ he $\mathrm{s}$ tructure o $\mathrm{f}$ an automated machine tool system and for which

$$
P_{i}=\left\lfloor\wedge_{L} \pi_{l}^{i}\right\rfloor
$$

\section{The matrix between the elements of an automated machine tool system}

The $\mathrm{p}$ redicate $\mathrm{m}$ atrix of $\mathrm{t}$ he $\mathrm{r}$ elationship $\mathrm{b}$ etween $\mathrm{t}$ he elements $a_{x}, X \in\{X\} \quad$ and $\pi_{l}, l \in\{L\} \quad$ the automated machine t ool s ystem s ets $t$ he $t$ echnological capabilities of the equipment used:

$$
M=\left\{\begin{array}{ccccccc} 
& \pi_{1}, & \pi_{2}, & \ldots, & \pi_{l}, & \ldots, & \pi_{L} \\
a_{1} & y_{11}, & y_{12}, & \ldots, & y_{1 l}, & \ldots, & y_{1 L} \\
a_{2} & y_{21}, & y_{22}, & \ldots, & y_{2 l}, & \ldots, & y_{2 L} \\
\ldots & \ldots & \ldots & \ldots & \ldots & \ldots & \ldots \\
a_{x} & y_{x 1}, & y_{x 2}, & \ldots, & y_{x l}, & \ldots, & y_{x L} \\
\ldots & \ldots & \ldots & \ldots & \ldots & \ldots & \ldots \\
a_{X} & y_{X 1}, & y_{X 2}, & \ldots, & y_{X l}, & \ldots, & y_{X L}
\end{array}\right.
$$

From formula $1 \mathrm{f}$ or a group of parts $d \in\left\{D_{2}\right\}$, it is obvious that:

$$
d=\widehat{N}_{N^{\prime}} p_{i}\left\lfloor\widehat{\wedge}_{L} \pi_{l}^{i}\right\rfloor
$$

for a group of parts $\left\{D_{2}\right\}$

$$
\left\{D_{2}\right\}=\wedge_{M} d_{j}\left\{\hat{N}_{N^{\prime}} p_{i}\left\lfloor\wedge_{L} \pi_{l}^{i}\right\rfloor\right\}
$$

for part nomenclature $\left\{D^{H}\right\}$

$$
\left.\left.\left\{D^{H}\right\}=\underset{2=1}{\forall} D_{2}\left[\wedge_{M} d{ }_{j} \hat{N}_{N^{\prime}} p_{i} \mid \wedge_{L} \pi_{l}^{i}\right]\right\}\right] .
$$

For e ach transition $\pi_{l}, l \in\{L\}$ (2), construct a vector $y_{l}=\left(y_{1 l}, y_{2 l}, \ldots, y_{x l}, y_{x l}\right)$. For each $\mathrm{t}$ ransition (2), construct a vector.

Its nonzero elements determine the equipment of the automated machine tool system $a_{x}, X \in\{X\}$, on which this transition can be implemented:

$$
\begin{gathered}
\pi_{1}=\left(y_{11}, y_{21}, \ldots, y_{x 1}, y_{X 1}\right) \\
\ldots \ldots \ldots . . . \ldots \ldots \ldots . . . . . . \\
\pi_{L}=\left(y_{1 L}, y_{2 L}, \ldots, y_{x L}, y_{X L}\right)
\end{gathered}
$$

We substituted vectors (6) into (1) for $P_{i}, i \in\left\{N^{\prime}\right\}$

$$
\begin{aligned}
& p_{i}=\pi_{1}^{i}\left(y_{11}, y_{21}, \ldots, y_{x 1}, \ldots, y_{X 1}\right) \wedge \\
& \wedge \pi_{2}^{i}\left(y_{12}, y_{22}, \ldots, y_{x 2}, \ldots, y_{x 2}\right) \wedge \\
& \text { } \wedge \text {.......................... } \\
& \wedge \pi_{l}^{i}\left(y_{1 l}, y_{2 l}, \ldots, y_{x l}, \ldots, y_{X l}\right) \wedge \\
& \wedge \pi_{L}^{i}\left(y_{1 L}, y_{2 L}, \ldots, y_{x L}, \ldots, y_{X L}\right)
\end{aligned}
$$

and after the transformations we got:

$$
p_{i}=\wedge \pi_{l}^{i}\left(y_{1 l}, y_{2 l}, \ldots, y_{x l}, \ldots, y_{X l}\right)
$$

or

$$
p_{i}=\wedge \pi_{l}^{i}\left(\underset{X}{\forall} y_{x l}\right)
$$

and for the detail

$$
\left.\left.d_{j}=\widehat{N}_{N^{\prime}} p_{i}\right\rfloor_{L} \pi_{l}^{i}\left(\underset{X}{\forall} y_{x l}\right)\right\rfloor
$$

For a group of parts $\left\{D_{2}\right\}$ :

$$
\left.\left\{D_{2}\right\}=\wedge_{M^{\prime}} d_{j}\left\{\underset{N^{\prime}}{\wedge} p_{i} \mid \wedge_{L} \pi_{l}^{i}\left(\forall_{X} y_{x l}\right)\right]\right\}
$$

for part nomenclature $\left\{D^{H}\right\}$ :

$$
\left.\left\{D^{H}\right\}=\underset{\tilde{a}=1}{\forall} D_{\tilde{a}}\left[\wedge \widehat{\Lambda}_{M} d_{j} \hat{N}_{N^{\prime}} p_{i}\left\lfloor\bigwedge_{L} \pi_{l}^{i}\left({ }_{X}^{\forall} y_{x l}\right)\right]\right\}\right] .
$$

If $\mathrm{t}$ he disjunction o $\mathrm{f}$ vectors $y_{x l}=0$ and $\mathrm{i} \mathrm{f}$ $\underset{X}{\forall} y_{x l}=0$, then the given nomenclature of parts $\left\{D^{H}\right\}$ cannot be manufactured by this automated machine tool system according to (8). 
We $\mathrm{g}$ ot a $\mathrm{p}$ redicate, where $\forall d_{j}-$ is the merge quantifier with domain $\mathrm{M}$ :

$$
\left.\psi\left\{D^{H}\right\}=\underset{M}{\forall} d_{j}=\left\{\hat{N}_{N^{\prime}} p_{i} \mid \wedge_{L} \pi_{l}^{i}\left({\underset{X}{X}}_{x l}^{\forall} y_{x l}\right)\right]\right\}
$$

The r esulting p redicate $\psi\left\{D^{H}\right\}=1$, if for each part $d_{j} \in\left\{D^{H}\right\}_{X}^{\forall} y_{x l}^{i} \neq 0$ there ar e manyt ransitions $\pi_{l}, l \in\{L\}$ in the accepted equipment of the automated machine to ol s ystem $a_{x}, X \in\{X\}$, which is cap able of processing any part $d_{j}, j=\overline{1, M}$.

The analysis of the model described in (9) shows that the number of variants of the structure of the automated machine tool system is large and therefore, to reduce the number of variants, it is possible to use the target nonlinear function of the MNP ACC design:

$$
F \rightarrow \min [\{X\} \wedge\{T\} \wedge\{O\} \wedge\{I\}],
$$

if

$$
\psi\left\{D^{H}\right\}=1
$$

The work [12] confirms the correctness and validity of function (10).

Minimize a lternative structures o $\mathrm{ft}$ he a utomated system in order to obtain foreseeable set of options, can be isomorphic mapping relationships between the elements of ACC on the graph $\mathrm{G}$ *.

Thus, we $g$ et a dialectical $r$ elationship b etween th $e$ structures of the nomenclature of parts and an automated machine tool system.

For a $\mathrm{n}$ automated machine $\mathrm{t}$ ool s ystem, it can b e expressed through the $\mathrm{p}$ roperties o $\mathrm{fel}$ ements that implement the structure of the system (table 1). Based on the properties of the el ements of an automated system, technological co nditions ( TC) can $b$ e f ormulated $t$ hat will a llow synthesizing a lternative structures of the designed automated system, i.e.:

$$
G^{*}=\left(X^{\prime}, T^{\prime}, O^{\prime}, I^{\prime}\right)^{\{T Y\}} \Rightarrow G^{* *}=\left(X^{\prime \prime}, T^{\prime \prime}, O^{\prime \prime}, I^{\prime \prime}\right),
$$

where $\{T Y\}$ is a set of formalized technological conditions, which generates a graph of relations, on the basis of which a matrix of relations is built (Fig. 1) and a formalized description of technological conditions is given.

Let us co nsider $t$ echnological conditions of $t$ wo types: particular and generalized.

Consider $t$ he pr ocess $\mathrm{c}$ onditions a re of $\mathrm{t}$ wo $\mathrm{t}$ ypes: partial and generalized.

Particular te chnological c onditions a re a pplied between el ements o $\mathrm{ft}$ he $\mathrm{s}$ et o $\mathrm{ft}$ he $\mathrm{s}$ ame $\mathrm{n}$ ame, an $\mathrm{d}$ generalized conditions are ap plied between el ements of unlike sets.

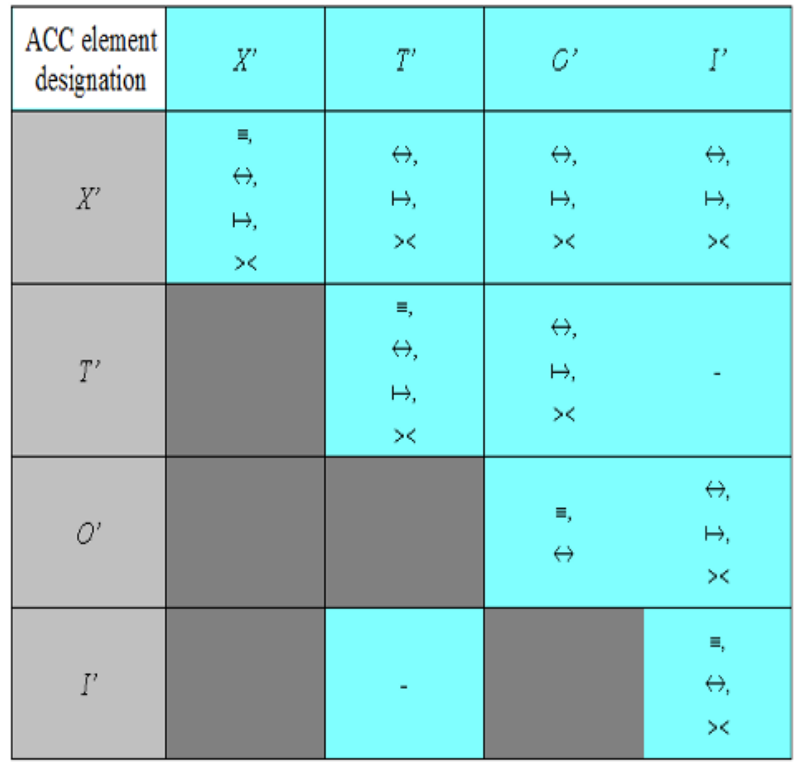

Fig. 1. Matrix of relations between ACC elements

At the same time, it is taken into account that $\mathrm{dj}$ is a complex part, which, in terms of its structural and technological ch aracteristics and $p$ arameters, $r$ epresents all the details of the group for which the ACC is designed. $\mathrm{F}$ or e xample, the $\mathrm{c}$ ompatibility $\mathrm{r}$ elationship between $\mathrm{t}$ he workpiece an $\mathrm{d} t$ he ACC eq uipment i s formally described:

$$
\begin{aligned}
& \forall d_{j} \underset{X}{\forall} a_{x} \exists S_{S_{d}} \exists S_{S_{x}} \ni P\left\{\left(d_{j}\left[S_{d}^{1}=\text { shaft }\right] \equiv a_{x}\left[S_{x}^{1}=\text { turning }\right]\right) \wedge\right. \\
& \left.\wedge\left(d_{j}\left[S_{d}^{3}\right] \geq a_{x}\left[S_{x}^{2}\right)\right) \wedge\left(d_{j}\left[S_{d}^{4}\right] \geq a_{x}\left[S_{x}^{3}\right]\right) \wedge\left(d_{j}\left[S_{d}^{5}\right] \leq a_{x}\left[S_{x}^{4}\right]\right)\right) \Rightarrow \\
& \Rightarrow\left\lfloor d_{j} \leftrightarrow a_{x}\right\rfloor
\end{aligned}
$$

Among the set of equipment on the basis of TU (12) for the part $d_{j} \in\left\{D^{H}\right\}$ under consideration, a s ubset of machines ca $n b$ e d istinguished, acco rding $t$ ot heir parameters, cap able of e nsuring the p rocessing of $t$ his part in accordance with the specified quality parameters.

Thus, by (12), taking into account the graph of relations, we can formulate the compatibility conditions for any pair of elements.

Table 1. Matrix of properties of the main elements of the machine tool system (fragment)

\begin{tabular}{|c|l|c|c|}
\hline $\begin{array}{c}\text { ACC } \\
\text { element }\end{array}$ & \multicolumn{1}{|c|}{ Element property } & $\begin{array}{c}\text { Property } \\
\text { name } \\
\text { notation }\end{array}$ & $\begin{array}{c}\text { Property } \\
\text { value } \\
\text { notation }\end{array}$ \\
\hline & Processing precision & $S_{x}^{1}$ & {$\left[S_{x}^{1}\right]$} \\
& $\begin{array}{l}\text { Roughness of } \\
\text { processing }\end{array}$ & $S_{x}^{2}$ & {$\left[S_{x}^{2}\right]$} \\
$\begin{array}{c}\text { Machin } \\
\text { tool } \\
(\text { set } \\
\{X\})\end{array}$ & Geometric parameters & $S_{x}^{3}$ & {$\left[S_{x}^{3}\right]$} \\
& Processing method & $S_{x}^{4}$ & {$\left[S_{x}^{4}\right]$} \\
& Power characteristics & $S_{x}^{5}$ & {$\left[S_{x}^{5}\right]$} \\
& & $S_{x}^{6}$ & {$\left[S_{x}^{6}\right]$} \\
\hline
\end{tabular}




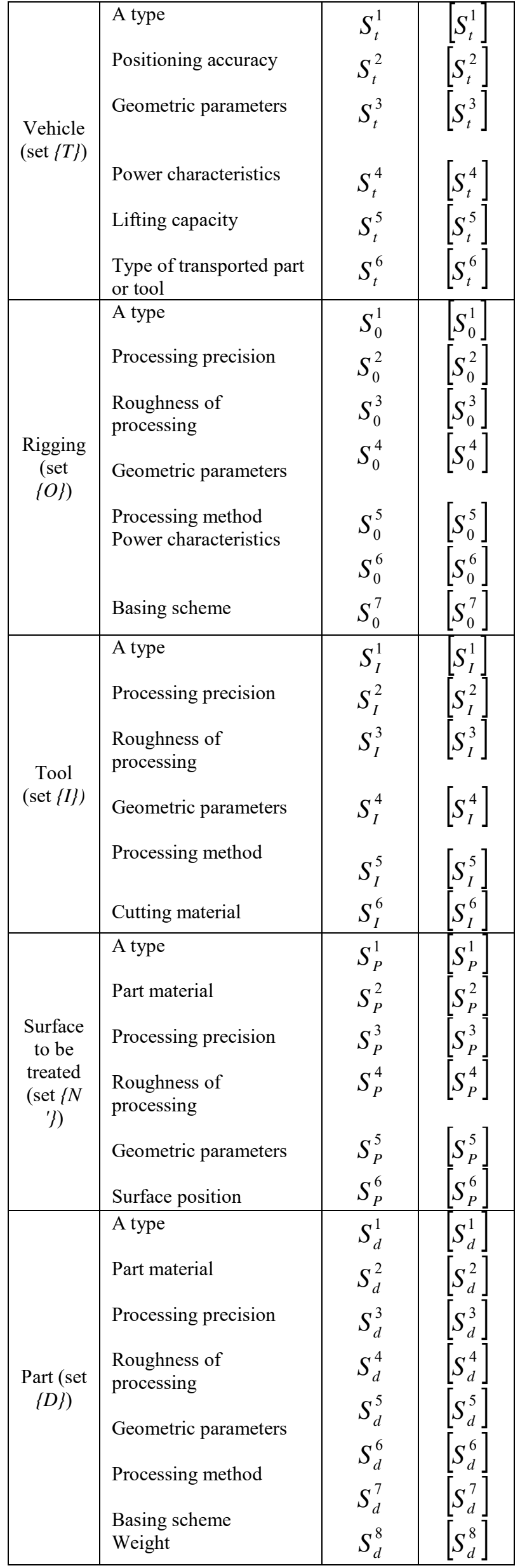

The te chnological c onditions o f c ompatibility between the part and the fixture can be represented as:

$$
\begin{aligned}
& \forall d_{j} \underset{o}{\forall} \operatorname{pr}_{o} \underset{S d}{\exists} S_{d} \underset{S_{o}}{\exists} S_{o} \ni P\left\{\left(d_{j}\left[S_{d}^{7}\right] \equiv p r_{o}\left[S_{o}^{7}\right]\right) \wedge\right. \\
& \left.\wedge\left(d_{j}\left[S_{d}^{5}\right]-p r_{o}\left[S_{o}^{4}\right] \leq k\right) \wedge\left(d_{j}\left[S_{d}^{6}\right] \equiv p r_{o}\left[S_{o}^{5}\right]\right)\right\} \Rightarrow \\
& \Rightarrow\left\lfloor d_{j} \leftrightarrow p r_{o}\right]
\end{aligned}
$$

where $\mathrm{k}$ i s a co efficient $\mathrm{t}$ hat $\mathrm{t}$ akes into acco unt the economically justified conditions for using this device. where $\mathrm{k}$ - factor $\mathrm{t}$ hat $\mathrm{t}$ akes into acco unt eco nomically viable conditions for the use of this device.

The technological conditions given in (12), (13) have the transitivity property:

$$
P\left[\left(d_{j} \leftrightarrow a_{x}\right) \wedge\left(d_{j} \leftrightarrow p r_{o}\right)\right] \Rightarrow\left(a_{x} \leftrightarrow p r_{o}\right)
$$

\section{Simulation of an automated machine tool system}

The following relation takes a special place among particular te chnological c onditions, $\mathrm{s}$ ince it is d ecisive not o nly in the t echnological s equence o $\mathrm{ft}$ he arrangement of the el ements of an a utomated machine tool system, but also in the direction of material flows, on which the structural structure of the entire automated system depends.

The $r$ atio of $r$ epetition $h$ as a s pecial $p$ lace am ong private process conditions, as is determined not only in the automated sequencing machine tool a rrangement of elements, but in the direction of material flow, on which the $\mathrm{s}$ tructural $\mathrm{c}$ onstruction of th e e ntire a utomated system.

The $t$ echnological sequence of pr ocessing on $t$ he equipment $a_{x}, a_{q}, x, q, \in\{X\}$ is d etermined from the expression:

$$
\begin{aligned}
& \underset{X}{\forall} a_{x} \underset{X}{\forall} a_{q} \underset{S_{x}}{\exists} S_{x} \underset{S_{q}}{\exists} S_{q} \ni P\left\{\left(P\left(a_{x}, \vec{U}, a_{q}\right) \wedge\right.\right. \\
& \left.\wedge\left(a_{x}\left[S_{x}^{2}\right] \geq a_{q}\left[S_{q}^{2}\right]\right) \wedge\left(a_{x}\left[S_{x}^{3}\right] \geq a_{q}\left[S_{q}^{3}\right]\right)\right\} \Rightarrow \\
& \quad \Longrightarrow\left[a_{x} \leftrightarrow a_{q}\right\rfloor
\end{aligned}
$$

The s equence in $\mathrm{t}$ erms of $\mathrm{t}$ he $\mathrm{d}$ irection of material flows i $\mathrm{n}$ a $\mathrm{n}$ a utomated machine tool $\mathrm{s}$ ystem $\mathrm{c}$ an $\mathrm{b}$ e determined from the technological condition connecting the elements of the transport system $b_{t} t \in\{T\}$ and the main technological equipment $a_{x}, x \in\{X\}$ :

$$
\begin{aligned}
& \underset{T}{\forall} b_{t} \underset{X}{\forall} \text { ax } \underset{S_{t}}{\exists} \underset{S_{S_{x}}}{\exists} S_{x} \text { э } P\left\{\left(P\left(b_{t}, \vec{U}, a_{x}\right) \wedge\right.\right. \\
& \left.\wedge\left(b_{t}\left[S_{t}^{3}\right] \equiv a_{x}\left[S_{x}^{4}\right]\right) \wedge\left(b_{t}\left[S_{t}^{4}\right] \equiv a_{x}\left[S_{x}^{6}\right]\right)\right\} \Rightarrow \\
& \Rightarrow\left[b_{t} \mapsto a_{x}\right]
\end{aligned}
$$

The a nalysis s howed that $\mathrm{t}$ he generalized technological co nditions were obtained on the b asis of the synthesis of compatibility and succession properties, 
and $\mathrm{s}$ ince $\mathrm{t}$ he $\mathrm{c}$ ompatibility $\mathrm{c}$ ondition $\mathrm{c}$ ontains a $\mathrm{n}$ equivalence $\mathrm{c}$ ondition in an i mplicit form, then the verification of the existence of generalized technological conditions $f$ or $t$ he el ements of $t$ he $s$ ame $n$ ame of an automated system is the establishment of the direction of material flows between them, and for dissimilar elements - technological adequacy.

The elements of the automated system interact during processing when the following condition (movement of material $f$ lows in $t$ he a utomated $s$ ystem) a nd th $e$ compatibility of technological parameters are met.

For $\mathrm{t}$ wo $\mathrm{d}$ issimilar o bjects, a generalized technological condition will be valid:

$$
\begin{aligned}
& \underset{T}{\forall} b_{t} \underset{X}{\forall} \operatorname{ax} \underset{S_{t}}{\exists} S t \underset{S_{x}}{\exists} S_{x} \ni P\left\{\left(P\left(b_{t}, \vec{U}, a_{x}\right) \wedge\left(\mid b_{t}\left[S_{t}\right] \equiv a_{x}\left[S_{x}\right]\right)\right\} \Rightarrow\right. \\
& \Rightarrow\left[b_{t}><a_{x}\right]
\end{aligned}
$$

Expression ( 17), ba sed on the pr eviously de fined graph $G(Z, U, P)$, a llows us to b uild a $\mathrm{g}$ eneralized technological $\mathrm{c}$ ondition $\mathrm{f}$ or $\mathrm{s}$ everal e lements o fa $\mathrm{n}$ automated system cap able o f i mplementing a cer tain technological function, the consequence of which is transitivity:

$$
\left\lfloor\left(p r_{o}><a_{x}\right) \wedge\left(b_{t} \overline{>} a_{q}\right)\right]
$$

The t ruth of expression (18) provides the a bility to choose the structure o fa $\mathrm{n}$ au tomated machine $\mathrm{t}$ ool system, as shown in Fig. 2.

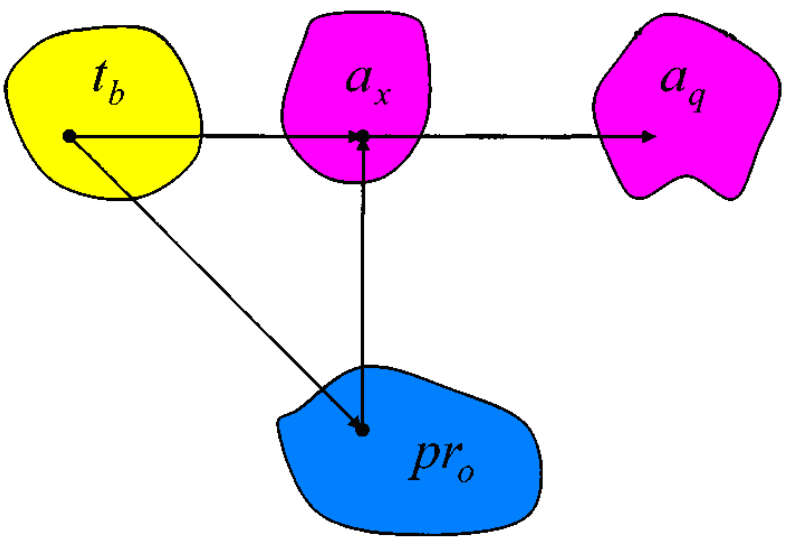

Fig. 2. The choice of elements of an automated system depending on technological conditions.

The $\mathrm{r}$ esulting $\mathrm{s}$ tructure of the a utomated s ystem satisfies condition (9), makes it $p$ ossible to use various target design functions to obtain a quasi-optimal option, without contradicting (10).

By a pplying t he $\mathrm{i}$ nvestigated de sign pr ocedures tailored to the specific optimization objective there is a possibility of a variety of options to get the structure of quasi-optimal automated machining system.

The $\mathrm{s}$ equence of mathematical modeling o $\mathrm{ft}$ he process of creating an automated machine tool system is shown in Fig. 3.

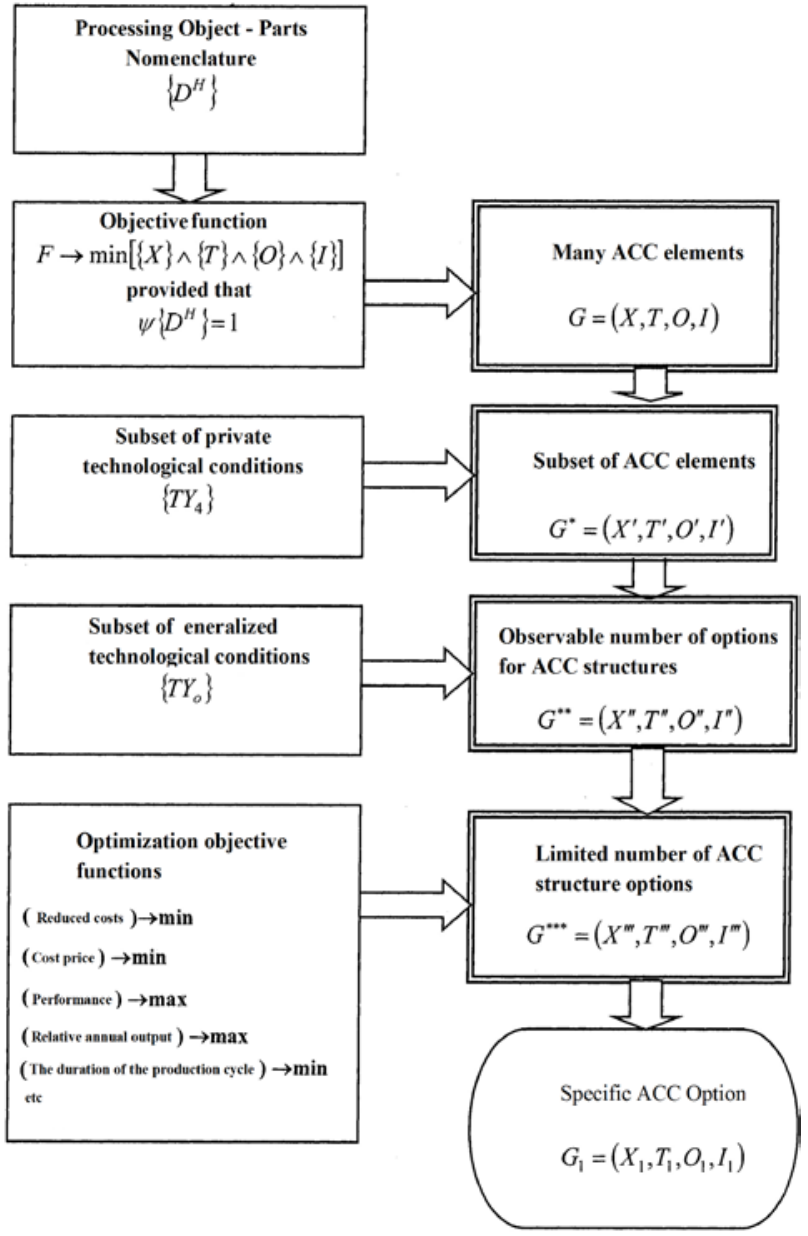

Fig. 3. Mathematical modeling of the process of designing an automated system.

\section{Conclusion}

The $\mathrm{p}$ aper $\mathrm{d}$ iscusses $\mathrm{t}$ he $\mathrm{g}$ eneralized $\mathrm{t}$ echnological conditions obt ained on $t$ he basis of $t$ he $s$ ynthesis of compatibility a nd follow-up pr operties, with $\mathrm{t}$ he existence of generalized technological conditions for the elements of the a utomated s ystem o f t he same na me being acco unted for simultaneously. The interaction of the elements of an a utomated system during processing, where $t$ he $\mathrm{c}$ ondition o f c ompatibility o f te chnological parameters is met, was investigated.

The analysis o $\mathrm{fth}$ e functional and technological structure of the automated machine tool system of multiproduct manufacturing was carried ou $t$ ba sed on $t$ he relationships between its main elements, which describe the $t$ echnological en vironment an $d$ ar e a s ubject o $f$ system research.

\section{References}

1. R.I. Vakhitova, E.B. Dumler, F.Z., Bulyukova, E.F. Zakharova, Increasing the efficiency of diversified production based on modeling automated technological equipment: monograph (Almetyevsk, AGNI, 2019, 92 p)

ISBN: 978-5-94454-039-3 
2. E.B. Dumler, Voronezh S tate T echnical U niversity Bulletin, 3(5) (2007) [in Russia] ISSN 1729-6501

3. Yu.M. Solomentsev, V .G. Mitrofanov, A.V. Kapitanov, Automated machining systems, organization of operation of metalworking tools (Interdisciplinary information service, 4, 2012).

4. I. Shakhnovich, M. Sheikin, Electronics: S cience, Technology, Business, 4, 135 (2014)

5. M.O. Kalinin, V.I. Kalinina. Control technology of functional stability of control information systems of mechanical engineering (In th e c ollection: Prospective D evelopment of S cience, E ngineering and Technologies, 2014)

ISBN: 978 -5-9905939-3-0V.V. Dodonov. Mechanical engineering, 12, (2011) ISSN: 0536 1044

6. V.V. Dodonov. Engineering J ournal: $\mathrm{S}$ cience a nd Innovation, 2(38) (2015) DOI: $10.18698 / 2308-6033-2015-2-1370$

7. N.I. D yatchin Engineering technology and its development as a science (In the book : M odern technological s ystems i $\mathrm{n} \mathrm{m}$ echanical engineering. Abstracts of reports, 2006)

8. A.A. Tarasov, V.N. Krutov, V.A. Treyal, A.A. Smirnov, Instruments and t echnologies, 29, (2010) [in Russia]

9. G.B. Burdo, A.N. Bolotov, N.V. Ispiryan, S.R. Ispiryan, Hybrid integrated automated design and management systems (In th e $\mathrm{c}$ ollection: Development of technical sciences in the modern world. Collection of scientific papers on the basis of the international scientific and practical conference, 2017).

10. S.G. Mitin, P.Yu. Bochkarev, Bulletin o ft he Saratov, State Technical U niversity, P.2, 1(75) (2014) [in Russia]

11. V.V. Dodonov, Proceedings of h igher ed ucational institutions, Mechanical engineering, 12, (2012) 